\title{
PERANCANGAN SASARAN MUTU LEMBAGA SERTIFIKASI PERSONEL DENGAN BALANCE SCORECARD
}

\author{
SIK SUMAEDI DAN MEDI YARMEN \\ Pusat Penelitian Sistem Mutu dan Teknologi Pengujian - LIPI \\ E-mail: sik_s_01@yahoo.com, siks002@lipi.go.id
}

\begin{abstract}
ABSTRAK
ISO/IEC 17024 menyusun Bodies Operating Certification of Person untuk mengadopsi dokumen sistem manajemen mutu berdasarkan ISO 9001: 2008. Bodies Operating Certification of Person yang mengiplementasikan ISO 9001 sistem dokumentasi harus memiliki tujuan mutu. Tujuan mutu diharapkan akan menjadi prioritas dalam indikator kemampuan institusi. Selanjutnya, ketikan tujuan mutu dicapai, kemampuan institusi akan menjadi bagus juga. Masalahnya tujuan mutu dalam ISO 9001 dijelaskan secara umum. Kondisi ini mendorong Bodies Operating Certification of Person untuk mengidentifikasi prioritas ruang lingkup tujuan mutu. Balance Score Card, metode strategis pengukuran performansi manajemen yang terdiri dari 4 perpektif (keuangan, konsumen, proses internal, pembelajaran dan pertumbuhan) yang terbukti efektif sebagai solusi untuk masalah tersebut. Penelitian ini untuk mengimplementasikan ruang lingkup manajemen performansi Balance Score Card dalam tujuan mutu Bodies Operating Certification of Person. Penelitian ini penting melihat tidak ada penelitian sebelumnya yang mengimplementasikan Balance Score Card dalam Bodies Operating Certification of Person. Hasil dari penelitian ini menunjukan Balance Score Card berdasarkan rancangan tujuan mutu dengan total 12 tujuan mutu yang terdiri dari 1 tujuan mutu perspektif keuangan, 5 tujuan mutu perspektif konsumen, 3 tujuan mutu perspektif proses internal, dan 3 tujuan mutu perspektif pembelajaran dan pertumbuhan.
\end{abstract}

Kata kunci: ISO 9001, tujuan mutu, balance score card, standar operasi sertifikasi perorangan

\begin{abstract}
ISO/IEC 17024 directs Bodies Operating Certification of Person to adopt documented quality management system according to ISO 9001:2008. Bodies Operating Certification of Person that implement ISO 9001 documentation system should have quality objective. Quality objective is wished to be appropriated with institution performance indicators. Therefore, when quality objective is achieved, the institution performance is also good. The problem is quality objective in ISO 9001 is generally explained. This condition pushes Bodies Operating Certification of Person to identify the appropriate quality objective framework. Balance Score Card, a strategic performance measurement management framework that consist of 4 perspectives (financial, customer, internal process, learning and growth) that effectively proven could be solution for that problem. This research is to implement Balance Score Card performance management framework in Bodies Operating Certification of Person's quality objective. This research is important considering there is no previous research that implement Balance Score Card in a Bodies Operating Certification of Person. The research result shows Balance Score Card based quality objective design with totally 12 quality objectives that consist of 1 financial perspective's quality objective, 5 customer perspective's quality objectives, 3 internal process perspective's quality objectives, and 3 learning and growth perspective's quality objectives.
\end{abstract}

Key words: ISO 9001, quality objective, balance score card, bodies operating certification of person

\section{PENDAHULUAN}

ISO/IEC 17024:2003 mengarahkan agar Lembaga Sertifikasi Personel (LSP) mengelola dokumentasi sistem manajemennya berbasis ISO 9001 (ISO 17024, 2003). Hal ini wajar, mengingat telah banyak penelitian yang membuktikan bahwa penerapan ISO 9001 secara konsisten akan memberikan banyak manfaat baik dari sisi internal organisasi seperti peningkatan mutu, produktivitas, efektifitas, dan kinerja, maupun dari sisi eksternal seperti peningkatan image dan peluang pemasaran (Sampaio dkk, 2009). ISO 9001 mensyaratkan agar LSP menetapkan sasaran mutu (ISO 9001, 2008). Sasaran mutu adalah sesuatu yang dicari, atau dikehendaki, yang berkaitan dengan mutu (ISO 9000, 2005). Seluruh proses dan aktivitas dalam suatu sistem manajemen mutu diarahkan untuk mencapai sasaran tersebut. Dengan kalimat berbeda dapat disebutkan bahwa sasaran mutu merupakan indikator performa bagi sistem manajemen mutu suatu LSP. 
ISO 9001 mengarahkan agar sasaran mutu dapat diukur dan konsisten dengan kebijakan mutu (ISO 9001, 2008). ISO 9004 sebagai standar intrepretasi ISO 9001 untuk perbaikan berkelanjutan mengarahkan agar organisasi tidak hanya memperhatikan pencapaian proses saja, tetapi juga performa kinerja organisasi lainnya, termasuk performa keuangan. Hal ini berarti sasaran mutu haruslah selaras dengan tujuan kinerja LSP. Saat sasaran mutu tercapai, idealnya tujuan-tujuan kinerja LSP dapat tercapai pula. Dan pada akhirnya, LSP akan mencapai posisi yang sesuai dengan visinya. SP PUSTAN LIPI merupakan sebuah lembaga sertifikasi personel milik pemerintah yang bergerak pada bidang sertifikasi auditor sistem mutu. Sebagai lembaga sertifikasi personel, SP PUSTAN LIPI telah terakreditasi ISO/IEC 17024 oleh Komite Akreditasi Nasional (KAN). Untuk memenuhi persyaratan ISO/IEC 17024, SP PUSTAN LIPI secara periodik menetapkan sasaran mutu. Meskipun demikian, sasaran mutu yang ditetapkan oleh SP PUSTAN LIPI belumlah selaras dan terintegrasi dengan sasaran organisasi. Kondisi ini mengakibatkan pencapaian sasaran mutu LSP tidak berbanding lurus dengan pencapaian kinerja SP PUSTAN LIPI.

ISO 9001 maupun ISO 9004 hanya memberikan panduan umum tentang sasaran mutu. SP PUSTAN LIPI yang menginginkan pencapaian sasaran mutunya selaras dengan kinerja organisasi haruslah mencari kerangka pengukuran kinerja yang sesuai. Di sisi lain, SP PUSTAN LIPI adalah organisasi yang unik dikarenakan ia melibatkan pihak luar dalam proses intinya yaitu pengelolaan skema sertifikasi dan pengujian. Dalam kaitan itu, rumusan masalah penelitian ini adalah rancangan sasaran mutu yang mampu merepresentatifkan ukuran-ukuran kinerja dan berkorelasi dengan visi maupun proses SP PUSTAN LIPI. Permasalahan di atas akan diselesaikan dengan menggunakan pendekatan Balance Score Card. Balance Score Card diperkenalkan oleh Kaplan dan Norton sebagai jawaban atas hasil riset mereka terhadap 12 organisasi yang menyimpulkan bahwa pengukuran performa kinerja tradisional hanya fokus pada aspek keuangan yang membuat penilaian menjadi bias dan menjadikan fungsi pengukuran terpusat sebagai alat pengendalian, serta mengabaikan keterkaitan antara performa operasional dengan sasaran strategis organisasi pada semua level (Pienar dan Penzhorn, 2000).

Balance Score Card bukanlah sekedar tools untuk mengukur kinerja organisasi, tetapi ia adalah sebuah sistem pengukuran performa strategis (Budi Suprapto dkk, 2009). Ia menerjemahkan strategi organisasi menjadi sasaran, indikator, ukuran, target, dan inisiasi (action plan) organisasi yang jelas dalam empat perspektif yaitu perspektif keuangan, pelanggan, proses internal, dan pertumbuhan dan pembelajaran (Amin Widjaya Tunggal, 2009). Keempat perspektif menjawab pertanyaanpertanyaan mendasar sebagai berikut (Pineno, 2008): (1) Perspektif finansial. Ukuran-ukuran yang ada menjawab pertanyaan "Bagaimana organisasi seharusnya terlihat di mata shareholdersnya?", (2) Perspektif pelanggan. Ukuran-ukuran yang ada menjawab pertanyaan "Bagaimana organisasi seharusnya terlihat di mata pelanggannya?", (3) Perspektif proses internal. Ukuran-ukuran yang ada menjawab "Proses apa yang harus dijalankan organisasi secara sempurna?", (4) Perspektif pertumbuhan dan pembelajaran. Ukuran-ukuran yang ada menjawab "Bagaimana agar organisasi mempertahankan kemammpuannya untuk merubah dan meningkatkan?"

Balance Score Card mengarahkan agar indikator pengukuran dalam empat perspektif di atas terkoneksi pada visi organisasi (Pienar dan Penzhorn, 2000). Dalam kaitan tersebut organisasi harus mengidentifikasi dan menetapkan leading indicator, indikator-indikator yang memicu tercapainya ukuran keberhasilan organisasi dan lagging indicator, indikator-indikator ukuran keberhasilan organisasi. Penelitian ini bertujuan untuk merancang kerangka sasaran mutu SP PUSTAN LIPI dengan menggunakan pendekatan Balance Score Card. Lebih spesifik, penelitian ini bertujuan mengidentifikasi sasaran-sasaran, indikator-indikator, maupun ukuran yang dapat digunakan sebagai sasaran mutu SP PUSTAN LIPI dalam empat perspektif yaitu perspektif keuangan, pelanggan, proses internal, dan pertumbuhan dan pembelajaran.

\section{METODE}

Penelitian ini dilakukan melalui beberapa tahap. Tahap pertama, dilakukan identifikasi visi, misi, kebijakan, sasaran, panduan mutu, dan program kerja lembaga serta informasi-informasi lingkungan bisnis SP PUSTAN LIPI. Pengumpulan data dilakukan melalui studi dokumen, wawancara tidak terstruktur dan diskusi dengan personel yang ada.

Tahap kedua, dilakukan analisa nature business SP PUSTAN LIPI. Tahap ini bertujuan untuk memahami konsep bisnis lembaga sertifikasi personel sehingga dapat dijustisifikasi kemungkinankemungkinan sasaran-sasaran strategi/indikatorindikator yang harus diperhatikan. Dalam hal ini, tools yang digunakan adalah diagram Supplier- 
Input-Process-Output-Customer (SIPOC) mengingat Balance Score Card digunakan sebagai kerangka sasaran mutu.

Tahap ketiga, dilakukan analisa strategi. Tahap ini bertujuan untuk mengidentifikasi sasaran-sasaran strategi, indikator, ukuran yang kemudian dipetakan ke dalam empat perspektif. Input tahapan ini adalah hasil analisa Nature Business, visi, misi, kebijakan, sasaran mutu, dan program kerja lembaga.

Tahap keempat, dilakukan analisa Peta Strategi. Tahap ini bertujuan untuk melihat keterkaitan antar sasaran strategi/indikator dan hubungannya dengan pencapaian visi lembaga. Dengan diketahui keterkaitan dari setiap indikator, organisasi dapat menetapkan apakah leading dan lagging indicator dalam rancangan Balance Score Card.

Tahap kelima, validasi sasaran mutu. Tahap ini bertujuan untuk memastikan bahwa sasaran mutu yang digunakan telah sesuai dengan visi, misi, sasaran, kebutuhan maupun proses dari SP PUSTAN LIPI. Dalam hal ini, validasi dilakukan oleh peneliti senior SP PUSTAN LIPI dan pejabat Manajer Mutu saat SP PUSTAN LIPI diakreditasi oleh Komite Akreditasi Nasional.

\section{HASIL DAN PEMBAHASAN}

Pada bagian ini akan dijelaskan hasil-hasil tahapan perancangan sasaran mutu SP PUSTAN LIPI berbasis Balance Score Card.

\section{Nature of Business SP PUSTAN LIPI}

Sesuai metode penelitian, analisa nature of business dilakukan dengan menggunakan diagram SIPOC. Dalam hal ini, hasil pemetaan diagram SIPOC SP PUSTAN LIPI dapat dilihat pada gambar 1.

Pada aspek output terlihat bahwa produk akhir SP PUSTAN LIPI dapat dipandang dua hal yaitu sertifikat kelulusan (hasil ujian bagi yang tidak lulus) dan auditor sistem manajemen mutu yang tersertifikasi. Apabila output SP PUSTAN LIPI adalah sertifikat kelulusan maka konsumennya adalah auditor peserta ujian. Tetapi, apabila output SP
PUSTAN LIPI dipandang auditor sistem manajemen mutu yang tersertifikasi maka konsumennya adalah lembaga sertifikasi pengguna.

Dalam kaitan tersebut, SP PUSTAN LIPI haruslah memperhatikan kepentingan kedua output dan konsumennya. Hal ini disebabkan keduanya mempengaruhi jumlah auditor yang akan mendaftar pada lembaga. Apabila lembaga sertifikasi pengguna percaya pada SP PUSTAN LIPI, maka mereka akan mengarahkan para auditornya untuk tersertifikasi. Di sisi lain, apabila para auditor tersertifikasi puas mereka dapat mereferensikan pada para auditor lainnya untuk mendaftar. Oleh karena itu perancangan sasaran mutu harus memperhatikan tingkat kepuasan dan kepercayaan kedua customer tersebut serta faktor-faktor lain yang mempengaruhinya.

Pada aspek proses terlihat bahwa SP PUSTAN LIPI berada pada bisnis jasa yang melibatkan secara intensif para pelanggannya dalam proses operasi. Hal ini berimplikasi perancangan sasaran mutu harus memperhatikan ketepatan dan kecepatan proses pelayanan serta faktor-faktor lain yang mempengaruhinya.

Pada aspek input terlihat bahwa SP PUSTAN LIPI merupakan bagian dari organisasi pemerintahan. Hal ini berimplikasi perancangan sasaran mutu harus memperhatikan arah kebijakan pemerintahan, faktor kepemimpinan yang top down dan ikatan emosional dengan pegawai sebagai salah satu ciri khas organisasi pemerintahan, serta indikator-indikator kinerja organisasi pemerintahan lainnya.

Pada aspek supplier, SP PUSTAN LIPI melibatkan pihak luar pada proses intinya yaitu proses pembuatan dan pemeliharaan skema sertifikasi serta proses pengujian. Hal ini mutlak diperlukan sebagai pemenuhan persyaratan independensi lembaga. Oleh karena itu, perancangan sasaran mutu harus memperhatikan aspek komitmen dan kepuasan para supplier tersebut.

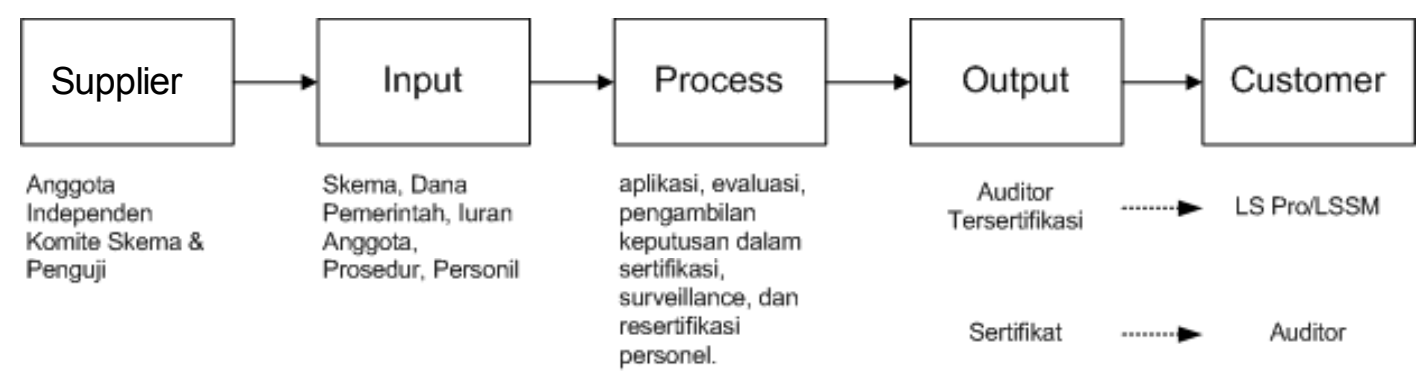

Gambar 1. Diagram SIPOC SP PUSTAN LIPI 
Tabel 2. Rancangan Sasaran Mutu Berbasis Balance Score Card SP PUSTAN LIPI

\begin{tabular}{|c|c|c|}
\hline Sasaran Strategis & Indikator & Ukuran \\
\hline \multicolumn{3}{|l|}{ Perspektif Keuangan } \\
\hline Peningkatan penerimaan iuran anggota & Jumlah penerimaan iuran anggota & $\mathrm{Rp}$ \\
\hline \multicolumn{3}{|l|}{ Perspektif Pelanggan } \\
\hline Peningkatan jumlah anggota baru & Jumlah angota baru & Jumlah \\
\hline Peningkatan retensi anggota lama & $\begin{array}{l}\text { Jumlah anggota yang mengundurkan diri } \\
\text { dari keanggotaan }\end{array}$ & Jumlah \\
\hline Peningkatan kepuasan anggota & $\begin{array}{l}\text { Tingkat kepuasan anggota berdasarkan } \\
\text { survei kepuasan anggota }\end{array}$ & Indeks \\
\hline Peningkatan kepercayaan LSSM/LSPRO & $\begin{array}{l}\text { Jumlah LSSM/LSPRO yang menggunakan } \\
\text { jasa anggota }\end{array}$ & Jumlah \\
\hline Penerbitan Direktori Auditor Indonesia & Ketepatan Jadwal penerimaan & $\%$ \\
\hline \multicolumn{3}{|l|}{ Perspektif Proses Internal } \\
\hline $\begin{array}{l}\text { Penerapan \& pemeliharaan Sistem ISO } \\
\text { 17024:2003 }\end{array}$ & Jumlah temuan audit KAN & Jumlah \\
\hline $\begin{array}{l}\text { Penurunan waktu pengiriman sertifikat } \\
\text { kelulusan }\end{array}$ & $\begin{array}{l}\text { Durasi waktu pengiriman minimal untuk } \\
\text { setiap anggota sejak diterimanya bukti } \\
\text { pelunasan biaya administrasi dan iuran } \\
\text { tahunan }\end{array}$ & Hari \\
\hline $\begin{array}{l}\text { Penurunan waktu penyampaian } \\
\text { informasi perubahan skema sertifikasi }\end{array}$ & $\begin{array}{c}\text { Durasi waktu penyampaian informasi } \\
\text { perubahan skema sertifikasi minimal }\end{array}$ & Hari \\
\hline \multicolumn{3}{|l|}{ Perspektif Pembelajaran \& Pertumbuhan } \\
\hline \multirow[t]{2}{*}{ Peningkatan partisipasi pegawai } & $\begin{array}{l}\text { Tingkat kepuasan personil berdasarkan } \\
\text { survei kepuasan pegawai }\end{array}$ & Indeks \\
\hline & $\begin{array}{l}\text { Tingkat pelaksanaan pelatihan program } \\
\text { pembinaan dibandingkan kebutuhan } \\
\text { pengembangan kompetensi pegawai } \\
\text { berdasarkan Training Needs Analysis }\end{array}$ & $\%$ \\
\hline $\begin{array}{l}\text { Peningkatan kepemimpinan } \\
\text { transformasional }\end{array}$ & $\begin{array}{l}\text { Tingkat kepemimpinan transformasional } \\
\text { berdasarkan survey kepemimpinan } \\
\text { transformasional }\end{array}$ & Indeks \\
\hline \multirow{2}{*}{$\begin{array}{l}\text { Peningkatan hubungan dengan anggita } \\
\text { komite luar LSP yang menguntungkan }\end{array}$} & Komposisi anggota luar dan anggota dalam & Rasio \\
\hline & $\begin{array}{l}\text { Tingkat kehadiran anggota komite luar } \\
\text { RSP rata-rata }\end{array}$ & \\
\hline
\end{tabular}

\section{Rancangan Balance Score Card}

Setelah dipahami nature business dari SP PUSTAN LIPI, langkah selanjutnya adalah membuat rancangan sasaran mutu berbasis Balance Score Card. Berdasarkan kajian terhadap indikator-indikator kinerja lembaga yang melingkupi seluruh elemen performa yang terdapat dalam diagram SIPOC, visi, misi, dan kebijakan SP PUSTAN LIPI maka tabel 2 merupakan rancangan sasaran mutu berbasis Balance Score Card SP PUSTAN LIPI.

Pada perspektif keuangan, sasaran mutu SP PUSTAN LIPI adalah peningkatan penerimaan iuran anggota dengan indikator jumlah penerimaan iuran anggota. Sasaran ini dipilih dengan pertimbangan pada era reformasi diharapkan organisasi-organisasi pemerintahan dapat terhindar dari ketergantungan APBN sekaligus mengoptimalkan skema Penerimaan Negara Bukan Pajak (PNBP). Dengan demikian, hal ini akan selaras dengan indikator keberhasilan kinerja SP PUSTAN LIPI di mata publik.

Pada perspektif pelanggan, terdapat lima sasaran mutu yaitu peningkatan jumlah anggota baru dengan indikator jumlah anggota baru, peningkatan retensi anggota lama dengan indikator jumlah anggota yang mengundurkan diri dari keanggotaan, peningkatan kepuasan anggota dengan indikator tingkat kepuasan anggota berdasarkan survey kepuasan anggota, peningkatan kepercayaan LSSM/LSPro dengan indikator jumlah LSSM/LSPro 
yang menggunakan jasa anggota, dan Penerbitan direktori auditor Indonesia dengan indikator ketepatan jadwal pengiriman. Pada perspektif ini, sasaran mutu disesuaikan dengan konteks SP PUSTAN LIPI di mana pelanggan dapat dilihat dari dua sudut yaitu auditor tersertifikasi (anggota) atau LSSM/LSPro sesuai dengan analisis diagram SIPOC sebelumnya.

Pada perspektif proses internal, terdapat tiga sasaran mutu yaitu penerapan dan pemeliharaan ISO/IEC 17024 dengan indikator jumlah temuan audit KAN, penurunan waktu pengiriman sertifikat kelulusan dengan indikator durasi waktu pengiriman sertifikat untuk anggota sejak diterimanya bukti pelunasan atau iuran tahunan, dan penurunan waktu penyampaian informasi perubahan skema sertifikasi dengan indikator durasi waktu penyampaian informasi perubahan tersebut. Pada perspektif ini, sasaran mutu dilihat dari sisi berjalannya sistem dan kecepatan waktu. Hal ini disesuaikan dengan konteks SP PUSTAN LIPI seperti terlihat dalam diagram SIPOC.
Pada perspektif pembelajaran dan pertumbuhan, sasaran mutu dilihat dari tiga aspek yaitu personel, kepemimpinan, dan pihak komite yang berasal dari luar organisasi. Hal ini didasari oleh pertimbangan bahwa kesinambungan dan kelancaran operasi SP PUSTAN LIPI amat bergantung pada ketiga aspek tersebut. Di sisi lain, pelibatan aspek nonmanusia amat jarang pada operasi SP PUSTAN LIPI. Adapun sasaran mutu dalam perspektif ini adalah peningkatan partisipasi pegawai dengan indikator tingkat kepuasan personel berdasarkan survey kepuasan personel, tingkat pelaksanaan pelatihan/program pembinaan dibandingkan dengan kebutuhan pelatihan/program pembinaan berdasarkan Training Needs Analysis (TNA), dan tingkat kehadiran rata-rata pegawai/bulan. Selain itu, sasaran mutu yang lain adalah peningkatan kepemimpinan transformasional dengan indikator tingkat kepemimpinan transformasional berdasarkan survey kepemimpinan transformasional dan peningkatan hubungan dengan anggota komite yang berasal dari luar dengan indikator komposisi anggota

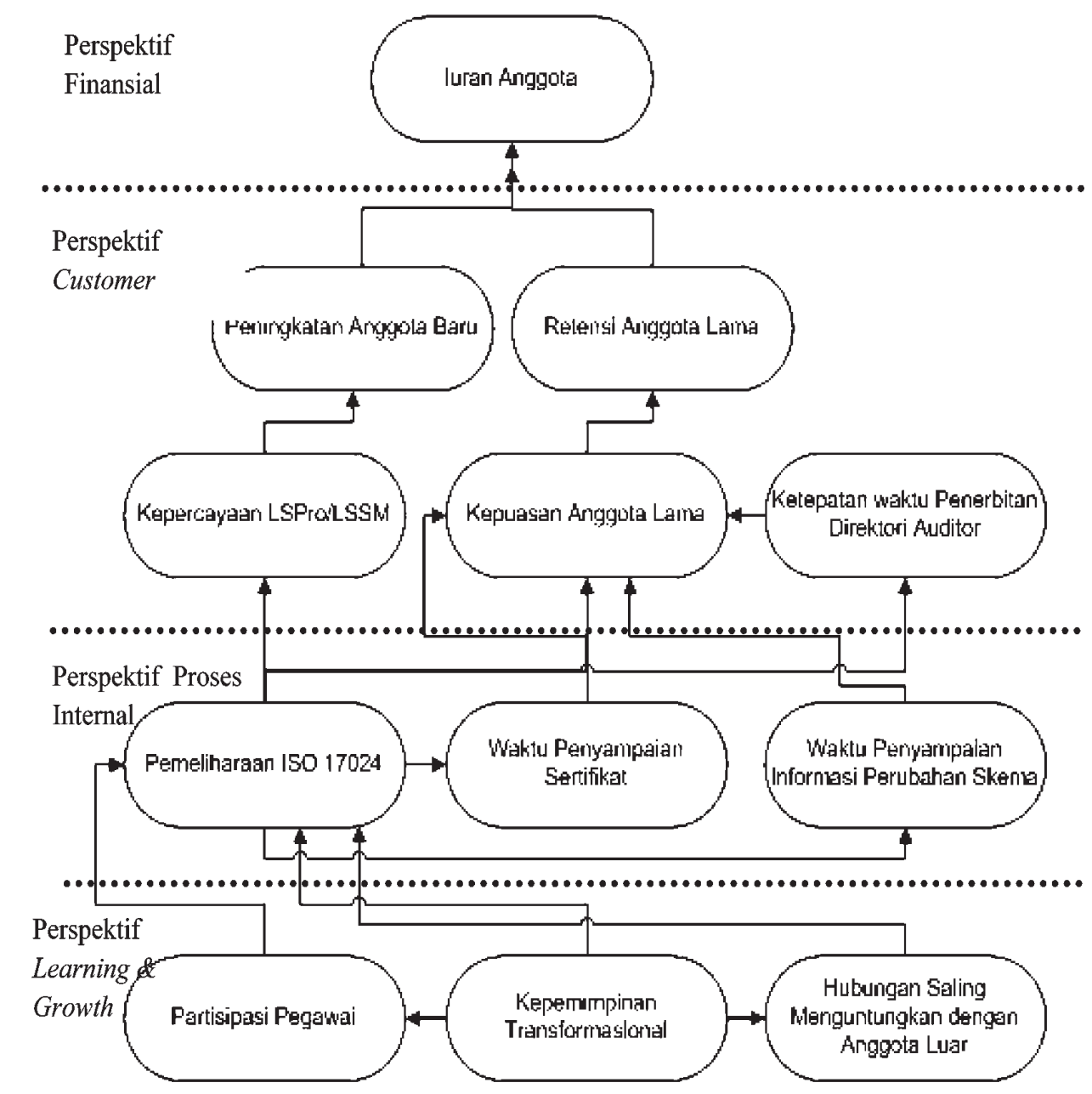

Gambar 2. Peta Strategi Sasaran Mutu SP PUSTAN LIPI 
luar dan dalam dan tingkat rata-rata kehadiran anggota komite yang berasal dari luar.

Dalam konteks SP PUSTAN LIPI, kepemimpinan transformasional menjadi penting mengingat pada organisasi pemerintahan, kekuasaan pimpinan dibatasi oleh birokrasi dan aturan-aturan lain yang lebih tinggi. Oleh karena itu, kinerja SP PUSTAN LIPI juga bergantung pada organisasi lain semisal Departemen Keuangan dalam konteks menjalankan programnya. Kepemimpinan transformasional diharapkan dapat mengubah pola pikir personel agar mampu menembus batas-batas birokrasi sehingga organisasi dapat bergerak dengan efektif.

\section{Peta Strategi}

Analisa peta strategi bertujuan untuk melihat apakah rancangan sasaran mutu yang dibuat memiliki koneksitas dan rasionalitas yang jelas. Selain itu, analisa peta strategi dapat digunakan untuk menentukan leading indicator dan lagging indicator yang penting digunakan dalam prioritasasi target dan waktu pencapaiaannya. Adapun Peta strategi rancangan Balance Score Card SP PUSTAN LIPI dapat dilihat pada gambar 2.

Pada peta strategi di atas dapat dilihat bahwa setiap sasaran mutu memiliki keterkaitan. Dalam hal ini "tanda panah" atau " $\rightarrow$ " menunjukkan bahwa sebuah sasaran mutu menyebabkan tercapainya sasaran mutu lainnya. Berikut ini adalah paparan keterkaitan tersebut.

Peningkatan kepemimpinan transformasional akan berakibat pada peningkatan partisipasi pegawai dan peningkatan hubungan saling menguntungkan dengan anggota luar. Peningkatan ketiga sasaran tersebut sendiri akan menyebabkan peningkatan pemeliharaan ISO/IEC 17024. Hal ini disebabkan kepemimpinan, partisipasi personel, dan partisipasi anggota luar merupakan faktor-faktor yang dapat mendorong keberhasilan penerapan ISO/IEC 17024.

Peningkatan pemeliharaan ISO/IEC 17024 akan mengakibatkan penurunan waktu penyampaian sertifikat dan penurunan waktu penyampaian informasi perubahan skema. Kondisi ini disebabkan dengan terpeliharanya ISO/IEC 17024 akan membuat proses-proses yang dilakukan menjadi efisien dan efektif sehingga memangkas konsumsi waktu yang tidak diperlukan.

Peningkatan pemeliharaan ISO/IEC 17024 juga akan mengakibatkan peningkatan kepercayaan LSSM/LSPro. Hal ini disebabkan sertifikat ISO/IEC 17024 menjamin bahwa proses-proses sertifikasi yang dilakukan oleh SP PUSTAN LIPI telah sesuai dengan standar internasional dan terjamin independensinya.
Selain itu, peningkatan pemeliharaan ISO/IEC 17024 mengakibatkan peningkatan ketepatan waktu penerbitan direktori auditor Indonesia.

Penurunan waktu penyampaian sertifikat, penurunan waktu penyampaian informasi perubahan skema dan peningkatan ketepatan waktu penerbitan direktori auditor Indonesia menyebabkan peningkatan kepuasan anggota lama. Hal ini disebabkan pada konteks usaha SP PUSTAN LIPI, dimensi terpenting yang diperhatikan oleh pelanggannya adalah ketepatan waktu. Peningkatan kepercayaan LSSM/ LSPro akan meningkatkan jumlah anggota baru yang mendaftar. Di sisi lain, peningkatan kepuasan anggota lama akan menyebabkan peningkatan retensi anggota lama. Dengan demikian, keduanya akan menyebabkan peningkatan penerimaan iuran anggota.

Peta strategi tersebut, juga dapat dilihat bahwa sebuah sasaran mungkin memiliki dua peran yaitu sebagai leading indicator dan lagging indicator. Sebagai contoh, indikator yang terdapat dalam sasaran "partisipasi pegawai" merupakan lagging indicator yang disebabkan oleh indikator yang terdapat "kepemimpinan transformasional". Tetapi, di sisi lain ia merupakan leading indicator bagi tercapainya indikator yang terdapat dalam sasaran "pemeliharaan ISO/IEC 17024:2003". Pada peta strategi, dapat dilihat bahwa leading indicator utama SP PUSTAN LIPI adalah indikator yang terdapat sasaran "kepemimpinan transformasional". Hal ini disebabkan SP PUSTAN LIPI merupakan organisasi pemerintah yang secara formal terikat pada aturan birokratis sehingga memerlukan kuatnya kepemimpinan agar organisasi dapat berubah. Sementara lagging indicator utama SP PUSTAN LIPI adalah indikator yang terdapat "iuran anggota". Sasaran ini dipilih sebagai sasaran akhir mengingat adanya semangat untuk membebaskan diri organisasi dari ketergantungan terhadap bantuan APBN. Diharapkan dengan semakin meningkatnya, iuran anggota maka SP PUSTAN LIPI akan semakin independen.

\section{Validasi Sasaran Mutu}

Sesuai dengan metode penelitian, sasaran mutu di atas di validasi oleh peneliti senior SP PUSTAN LIPI dan pejabat Manajer Mutu saat SP PUSTAN LIPI diakreditasi oleh Komite Akreditasi Nasional (KAN). Dalam hal ini, hasil validasi menyatakan bahwa sasaran mutu dapat digunakan oleh SP PUSTAN LIPI. Dengan demikian, sasaran mutu yang dirancang telah sesuai dengan visi, misi, sasaran, kebutuhan maupun proses dari SP PUSTAN LIPI. 


\section{SIMPULAN}

Hasil penelitian dapat disimpulkan bahwa Balance Score Card dapat digunakan sebagai kerangka sasaran mutu SP PUSTAN LIPI agar lembaga tersebut memiliki indikator performa sistem manajemen mutu yang selaras dengan indikator performa kinerja lembaga. Dalam hal ini, hasil perancangan menunjukkan 12 sasaran mutu berbasis Balance Score Card dengan rincian 1 sasaran mutu perspektif keuangan, 5 sasaran mutu perspektif pelanggan, 3 sasaran mutu perspektif proses internal, dan 3 sasaran mutu perspektif pembelajaran \& pertumbuhan. Setiap sasaran mutu memiliki sebuah indikator, kecuali sasaran mutu peningkatan partisipasi pegawai (3 indikator) dan sasaran mutu hubungan saling menguntungkan dengan anggota luar (2 indikator).

\section{DAFTAR PUSTAKA}

Farneti, Federica dan Guthrie, James 2008. "Italian and Australian Local Government: Balanced Scorecard Practices. A Research Note". Journal of Human Resource Costing \& Accounting, Vol. 12 No. 1 Hal. 4-13.

Gurd, Bruce dan Gao, Tian 2008. "Lives in The Balance: an Analysis of The Balanced Scorecard (BSC) in Healthcare Organizations”. International Journal of Productivity and Performance Management. Vol. 57 No. 1. Hal. 6-21.

ISO 9000:2005, International Standard, Fundamentals and vocabulary.

ISO 9001:2008, International Standard, Quality Management Systems Requirements.

ISO 17024:2003/Pedoman KAN 501:2003, International Standard, Conformity Assessment - General requirement for Bodies Operating Certification of Persons.

James, Wendy 2009. "Rationality, Institutionalism and Accounting Change. Understanding a Performance Management System within an Australian Public Sector Entity”. Journal of Accounting \& Organizational Change. Vol. 5 No. 3. Hal. 362-389.
Karapetrovic, S et al. 1998. "ISO 9001 Quality System: An interpretation For University". Int. J. Eng Ed. Vol. 14, No. 2, Hal. 105-118.

Lam, Steve Y.W 2002. "Role of Surveyors under ISO 9000 in the Construction Industry", Journal of Surveying Engineering, Vol. 128, No. 4.

Pienar, Heila and Penzhorn, Cecilia 2000. "Using the Balanced Scorecard to Facilitate Strategic Management at an Academic Information Service". Libri, 2000, Vol. 50, pp. 202-209.

Pineno, J. Charles 2008. "The Business School Strategy: Continuous Improvement by Implementing the Balanced Scorecard" Shenandoah University. Research in Higher Education Journal.

Sampaio, Paolo, dkk. 2009. "ISO 9001 Certification Research: Questions, Answers and Approaches". International Journal of Productivity and Performance Management. Vol. 26 No. 1, Hal. 38-58.

Shun-Hsing Chen dkk. 2006. "The Application of Balanced Scorecard in the Performance Evaluation of Higher Education”. The TQM Magazine. Vol. 18 No. 2. Hal. 190-205.

Suprapto, Budi dkk. 2009. "The Implementation of Balance Score Card for Performance Measurement in Small and Medium Enterprises: Evidence from Malaysian Health Care Services" The Asian Journal of Technology Management Volume 2, Number 2, PP. 37-49.

Vasilakis, Athanasios G. 2008. "Relative Balanced Measurement of Trainee Civil Servants: a Case Example from Greece". Benchmarking: An International Journal. Vol. 15 No. 6. Hal 677-692.

Widjaya Tunggal, Amin 2009. "Mengukur dan Mengelola Keberhasilan Usaha dengan Balance Score Card". Harvarindo. Jakarta.

Xiao-yun Chen dkk 2006. "Using the Balanced Scorecard to Measure Chinese and Japanese Hospital Performance". International Journal of Health Care Quality Assurance. Vol. 19 No. 4. Hal. 339-350.

Sotirakou, Tatiana dan Zeppou, Mary 2006. “Utilizing Performance Measurement to Modernize the Greek Public Sector". Management Decision. Vol. 44 No. 9. Hal. 1277-1304. 